\title{
COVID-19 and the World with Co-Morbidities of Heart Disease, Hypertension and Diabetes
}

\author{
Vijaya Anand Arumugam ${ }^{1 *}(\mathbb{D})$, Sangeetha Thangavelu ${ }^{1}(\mathbb{D}), Z^{2}$ areena Fathah ${ }^{2}$ (D), \\ Pavithra Ravindran ${ }^{1}$, Ann Mary Alappat Sanjeev ${ }^{1}$, Sunantha Babu ${ }^{1}$, \\ Arun Meyyazhagan ${ }^{3}$ (D), Mohd. Iqbal Yatoo ${ }^{4}$ (D) Khan Sharun ${ }^{5}$ (D), \\ Ruchi Tiwari $^{6}$ (D), Megha Katare Pandey ${ }^{7}$, Ranjit Sah ${ }^{8}$ (D) Ram Chandra9 \\ and Kuldeep Dhama ${ }^{10 *}$
}

\begin{abstract}
${ }^{1}$ Medical Genetics and Epigenetic Laboratory, Department of Human Genetics and Molecular Biology, Bharathiar University, Coimbatore - 641 046, India.

${ }^{2}$ King's College London, London, United Kingdom.

${ }^{3}$ Department of Life Sciences, CHRIST (Deemed to be University), Bengaluru - 560 029, Karnataka, India. ${ }^{4}$ Division of Veterinary Clinical Complex, Faculty of Veterinary Sciences and Animal Husbandry, Shuhama, Alusteng Srinagar, Sher-E-Kashmir University of Agricultural Sciences and Technology of Kashmir, Shalimar, Srinagar - 190 006, Jammu and Kashmir, India.

${ }^{5}$ Division of Surgery, ICAR-Indian Veterinary Research Institute, Izatnagar, Bareilly- 243 122, Uttar Pradesh, India. ${ }^{6}$ Department of Veterinary Microbiology and Immunology, College of Veterinary Sciences, UP Pandit Deen Dayal Upadhayay Pashu Chikitsa Vigyan Vishwavidyalay Evum Go-Anusandhan Sansthan (DUVASU), Mathura 281 001, Uttar Pradesh, India.

${ }^{7}$ Department of Veterinary Pathology, College of Veterinary Science, Durg - 491 001, Chhattisgarh, India.

${ }^{8}$ Tribhuvan University Teaching Hospital, Institute of Medicine, Kathmandu, Nepal.

${ }^{9}$ Department of Microbiology, School of Environmental Sciences, Babasaheb Bhimrao Ambedkar University, (A Central University) Vidya Vihar, Raebareli Road, Lucknow - 226 025, Uttar Pradesh, India.

${ }^{10}$ Division of Pathology, ICAR-Indian Veterinary Research Institute, Izatnagar, Bareilly - 243 122, Uttar Pradesh, India.
\end{abstract}

(C) The Author(s) 2020. Open Access. This article is distributed under the terms of the Creative Commons Attribution 4.0 International License which permits unrestricted use, sharing, distribution, and reproduction in any medium, provided you give appropriate credit to the original author(s) and the source, provide a link to the Creative Commons license, and indicate if changes were made. 


\begin{abstract}
Newly emerging severe acute respiratory syndrome coronavirus 2 (SARS-CoV-2) causing coronavirus disease 2019 (COVID-19) pandemic has now spread across the globe in past few months while affecting 26 million people and leading to more than 0.85 million deaths as on $2^{\text {nd }}$ September, 2020. Severity of SARS-CoV-2 infection increases in COVID-19 patients due to pre-existing health co-morbidities. This mini-review has focused on the three significant co-morbidities viz., heart disease, hypertension, and diabetes, which are posing high health concerns and increased mortality during this ongoing pandemic. The observed co-morbidities have been found to be associated with the increasing risk factors for SARS-CoV-2 infection and COVID-19 critical illness as well as to be associated positively with the worsening of the health condition of COVID-19 suffering individuals resulting in the high risk for mortality. SARS-CoV-2 enters host cell via angiotensin-converting enzyme 2 receptors. Regulation of crucial cardiovascular functions and metabolisms like blood pressure and sugar levels are being carried out by ACE2. This might be one of the reasons that contribute to the higher mortality in COVID-19 patients having co-morbidities. Clinical investigations have identified higher levels of creatinine, cardiac troponin I, alanine aminotransferase, NT-proBNP, creatine kinase, D-dimer, aspartate aminotransferase and lactate dehydrogenase in patients who have succumbed to death from COVID-19 as compared to recovered individuals. More investigations are required to identify the modes behind increased mortality in COVID-19 patients having co-morbidities of heart disease, hypertension, and diabetes. This will enable us to design and develop suitable therapeutic strategies for reducing the mortality. More attention and critical care need to be paid to such high risk patients suffering from co-morbidities during COVID-19 pandemic.
\end{abstract}

Keywords: SARS-CoV-2, COVID-19, Heart Disease, Hypertension, Diabetes, Pandemic, Co-morbidity

\section{Introduction}

Coronavirus disease 2019 (COVID-19), caused by newly emerged, single-stranded enveloped RNA virus namely severe acute respiratory syndrome coronavirus - 2 (SARS-CoV2), affects primarily the respiratory tract $^{1}$. The COVID-19 pandemic has been regarded as a serious pandemic that has adversely affected the health, social and economic status of the whole world, irrespective of the economic status of the countries ${ }^{2-4}$. COVID-19 has now spread to more than 210 countries across the globe, accounting for more than 0.85 million deaths out of 26 million confirmed cases reported till $2^{\text {nd }}$ September, 2020, and thus has created huge panic, havoc, and fear among worldwide population. Efforts to develop vaccines, drugs, therapies, immunomodulatory agents and strategies to enhance immunity against SARSCoV-2 infection are continuously being made along with adopting appropriate mitigation strategies to safeguard the health of the humans and save their lives from COVID-19 pandemic ${ }^{5-14}$.

The infection of SARS-CoV-2 affects all individuals irrespective of age. Men are more affected when compared to women, but that might be due to the higher chance of exposure ${ }^{15}$. However, the COVID-19 is indiscriminately affecting everyone; the co-morbidities are being suspected to pose a higher risk for decreasing the survival rate of the SARS-CoV-2 affected individuals. Various kinds of pee-existing diseases have been identified as co-morbidities in SARS-CoV-2 infection, which increases susceptibility, pose risks of more severity outcomes and deaths in COVID-19 patients by modulating virus-host interactions and host-immune responses, and also have some agedependent effects ${ }^{16-20}$. These include hypertension, diabetes, heart disease, chronic lung, kidney and liver diseases, malignancies, pro-inflammatory and pro-coagulative states, cerebrovascular diseases, smoking and others. The two life style associated conditions of overweight and obesity are identified as potential risks factors towards contributing to severe illness associated in COVID-19 patients ${ }^{18,21}$. The most common co-morbidities that have been identified with SARS-CoV-2 infection are heart diseases, hypertension, and diabetes ${ }^{20,22-25}$, which are the commonly found clinical conditions worldwide. Presence of diabetes and hypertension were found to be associated with a 2-fold while 
CVDs were associated with 3-fold increased requirement of intensive care and greater risk of severe disease, suggesting the importance of these co-morbidities as prognostic markers ${ }^{23}$.

Identification of various risk factors linked to COVID-19 deaths would aid in enhancing the treatment efficacy and lower down the mortality rates during COVID-19 pandemic. Medicines to treat heart diseases, anti-hypertension drugs for alleviating hypertension and glucose-lowering agents along with subscribing anti-viral treatments can reduce the risks of higher severity in COVID-19 patients having co-morbidities, however few of the associated limitations of their administration and potential interactions with anti-viral therapies need to be carefully evaluated.
In New York, among 5,700 COVID-19 patients, the most commonly reported comorbidities comprised of hypertension (56.6\%), obesity $(41.7 \%)$, and diabetes $(33.8 \%)^{22}$. Out of 1,023 deaths in China due to COVID-19, the higher fatality rate was associated with CVD, diabetes, chronic respiratory disease, and hypertension ${ }^{23}$. A systematic review that included 1,576 cases showed that the most prevalent co-morbidities in SARS-CoV-2 infected patients were hypertension (21.1\%), diabetes (9.7\%), CVD $(8.4 \%)$, and respiratory system disease $(1.5 \%)^{24}$; the combination of these co-morbidities were associated with mortality. Acute cardiac injury, pre-existing cardiovascular diseases (CVDs), hypertension, diabetes have been revealed

\section{ACE2 and COVID-19}

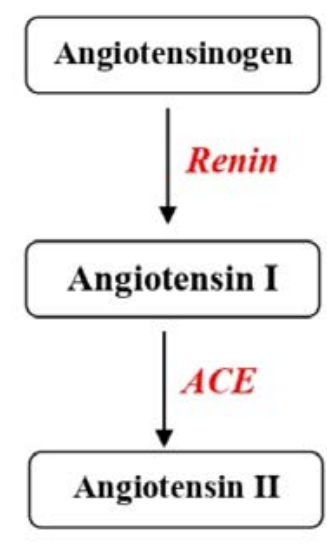

\section{COVID-19}
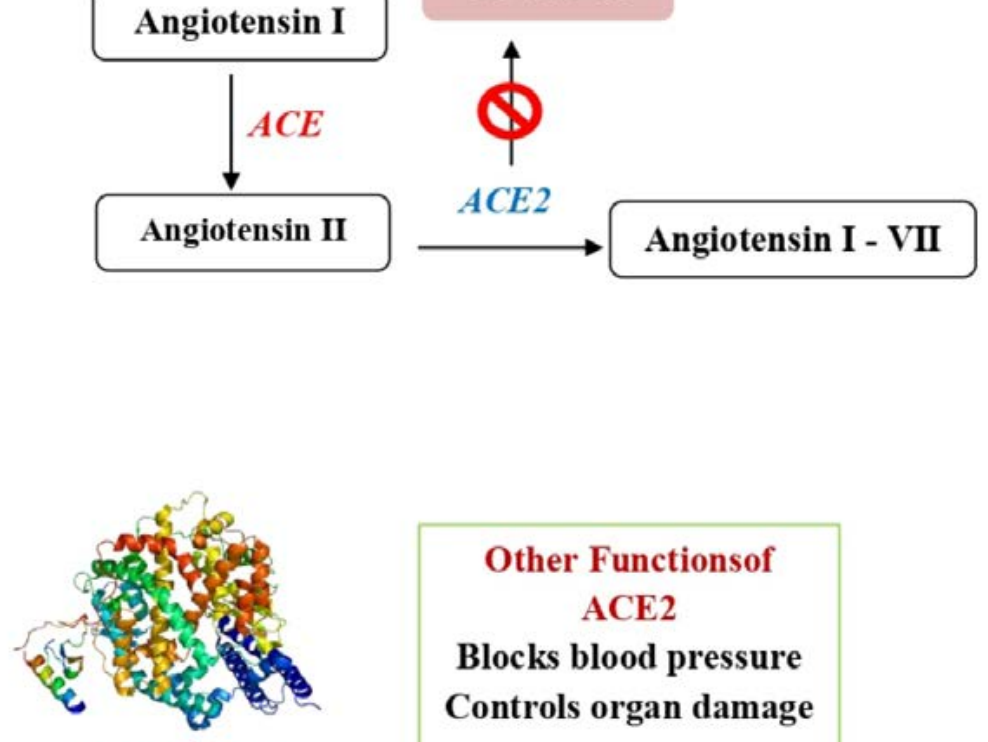

Other Functionsof

ACE2

Blocks blood pressure

Controls organ damage

\section{ACE2 enzyme}

\section{Structure}

Fig.1(a). COVID-19 and ACE2 
to be linked to COVID-19 clinical severity and survival of patients in a meta-analysis study by Momtazmanesh et al. ${ }^{26}$

Although this is clear that CVD, hypertension, and diabetes are substantial comorbidities for the incidence and fatality of COVID-19, our understanding of how these preexisting conditions increase the incidence and fatality is limited. The present article summarizes the evidence of the association between these conditions on COVID-19 incidence and mortality and discusses the possible mechanisms of how these conditions could increase the menace of infection as well as mortality in SARS-CoV-2 infection.

\section{COVID-19 and Heart Diseases}

Some patients having SARS-CoV-2 infection exhibited CVD problems ${ }^{27}$ and heart diseases as co-morbidities along with COVID-19 which influence prognosis and fatal outcomes during this ongoing pandemic ${ }^{20}$. Individuals who have suffered from heart failure (HF) are at higher risk of getting gripped by infections, which precipitate acute $\mathrm{HF}$ and increases mortality rates in such patients. In fact, about $40 \%$ of the mortality in COVID-19 cases was attributed to cardiac conditions including HF in Wuhan ${ }^{28}$.

Present era of COVID-19 pandemic is also playing critical role with co-morbidities of heart diseases and thus posing a challenge in managing heart disease patients in clinical practice, which need to be followed up with adopting appropriate guidelines for management and treatment of these critical patients ${ }^{29-32}$. It is suggested that early glucocorticoid anti-inflammatory therapy and immunoglobulin therapy may be of significant value to COVID-19 patients with heart diseases ${ }^{27}$. Long et $a .^{33}$ evaluated the cardiovascular

\section{Cytokines and COVID-19}

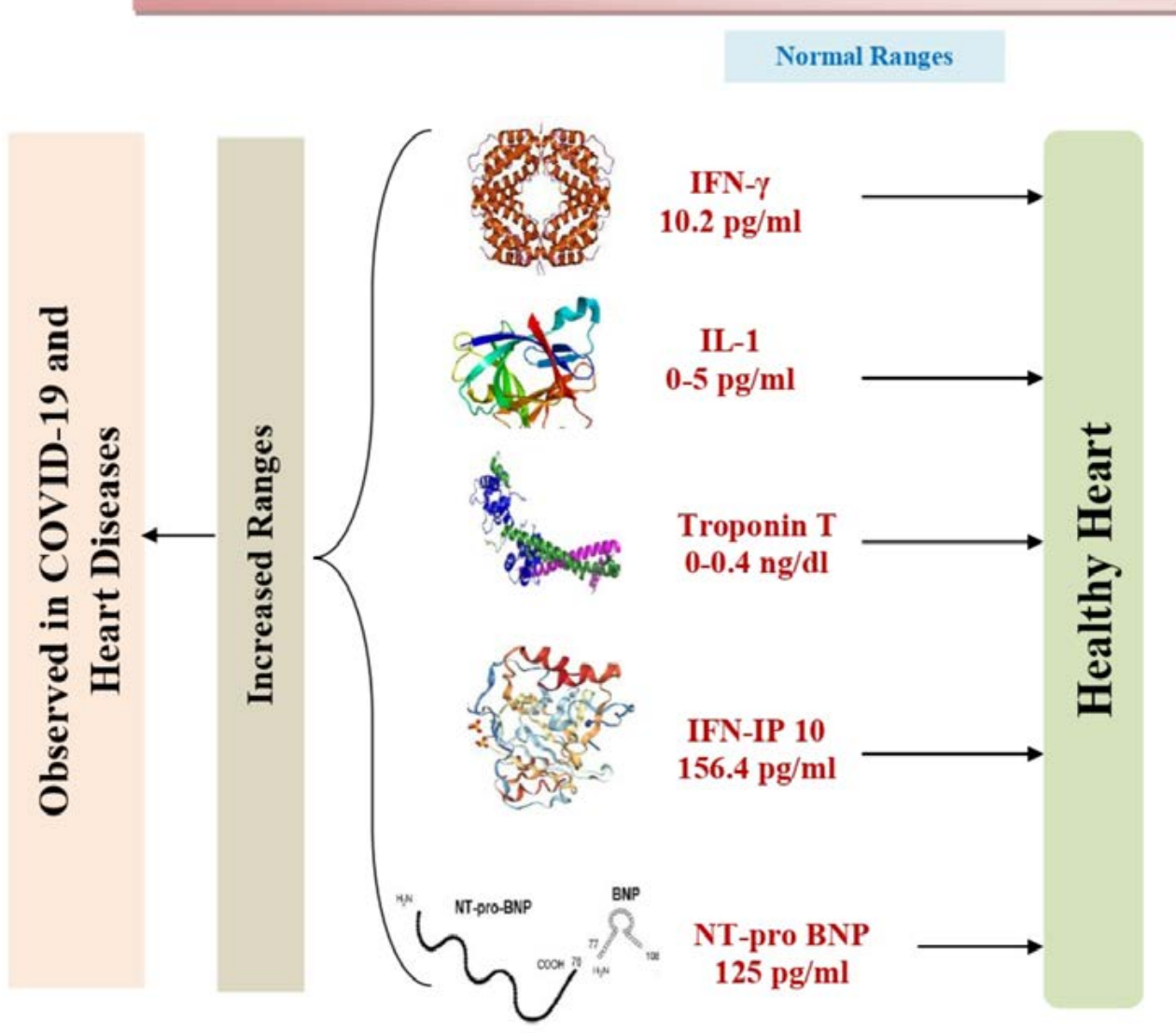

Fig.1(b). COVID-19 and ranges of Cytokines 
complications in COVID-19 patients such as injury in the myocardium, myocarditis, dysrhythmias, acute myocardial infarction, failure of heart, heart attack, and thromboembolic events in veins. The virus binds and enters through ACE2 and results in systemic inflammation, which leads to multiorgan dysfunction ${ }^{34}$. The cardiovascular system of the body gets further complicated by pulmonary difficulties and systemic inflammations. One of the major characteristic feature of COVID-19 that contributes to the pathophysiology is the overproduction of inflammatory cytokines [interleukin-6 (IL-6), tumour necrosis factor-alpha (TNF- $\alpha$ )]. This will result in systemic inflammation, lead to multiple organ dysfunction syndrome, thereby disturbing the cardiovascular system ${ }^{35,36}$.

Modes of CVD complications in COVID-19 have been reviewed by Bansa $\left.\right|^{37}$. Direct myocardial injury ${ }^{38}$, systemic inflammation ${ }^{39}$, altered ratio of myocardial demand and supply, rupture of plaque resulting in myocardial thrombosis, adverse effects of various therapies, electrolyte disturbances especially hypokalemia ${ }^{40}$ were proposed as possible mechanisms for cardiovascular complications. Mononuclear infiltration in the myocardium, and associated cardiomyocyte necrosis ${ }^{41}$ leading to, acute lung injury and acute respiratory distress syndrome (ARDS) result in strain on right side of heart and right ventricular (RV) dilation and dysfunction. The resultant elevated positive end expiratory pressure (PEEP) in the patient on ventilation can also deteriorate heart function ${ }^{42}$.

SARS-CoV-2 infection is linked to acute myocardial infarction and other cardiovascular emergencies ${ }^{34}$. Recent studies and case reports identified that COVID-19 can lead to acute cardiac injury and is associated with myocardial damage leading to increased complexity in patient treatment ${ }^{43}$. COVID-19 patients were found to show higher levels of troponin I, natriuretic peptides, diffuse myocardial dyskinesia, reduced left ventricular ejection fraction (LVEF) and high levels of IL-6. Hence, the study reported that such patients might build up severe cardiac complications including myocarditis and heart failure ${ }^{44,45}$. Babapoor-Farrokhran et al. $^{46}$ observed myocarditis, cardiac arrest, acute HF in patients suffering from COVID-19 and suggested SARSCoV-2 infection and cardiac diseases to be interrelated.
Various signaling pathways are regulating the cardiovascular functions, and the major among them is a notch signaling pathway, which is also involved in the regulation of biological reactions against viral infections. A recent study observed the possible ways to prevent COVID-19 is by targeting the notch signaling pathway ${ }^{47}$. Case reports have revealed COVID-19 significant effects on heart and vessels. SARS-CoV-2 interacts with cardiovascular system via a direct or indirect mode $^{48}$. The virus binds to ACE2, a membranebound zinc metallopeptidase, which is located in lungs as well as in the heart, which in turn is involved in the cleavage of angioten $\sin ^{49}$. ACE2 receptor expression gets elevated in postmyocardial infarction and diabetic patients thus posing increased risk for severe COVID-19 illness ${ }^{33}$. The regulation of crucial cardiovascular functions and metabolisms like regulation of blood pressure and sugar levels are being carried out by ACE2. Hence, SARS-CoV-2 affects cardiovascular system directly by targeting ACE2 ${ }^{50}$ (Fig. 1A). Apart from that, the alternative mechanism includes the effect on SARS-CoV- 2 infection by immune system indirectly through the myocardial vessels. Severe illness during COVID-19 entail a cytokine storm that pave way to coronary plaque instability, as like has been reported in SARS-CoV infection ${ }^{51,52}$. Besides, SARS-CoV or SARS-CoV-2 infected persons show lymphopenia which is linked for atherosclerosis development and unfavorable CVD outcomes ${ }^{48,49}$. Another study by Huang ${ }^{53}$ et al. has suggested that, the involvement of cardiac organ is an impediment that has been connected to COVID-19, even while pneumonic symptoms / signs are lacking. The patient with COVID-19 without symptoms of viral infections revealed cardiac concerns with elevated levels of $\mathrm{N}$-terminal pro-brain natriuretic peptide (NT-proBNP) and high-sensitivity troponin T detection ${ }^{53}$.

The infections due to SARS-CoV-2 can lead to pulmonary as well as systemic inflammation, which can cause the dysfunction of multiple organs that may be a higher risk for the patients. The progression of COVID-19 includes the wet lung disease and failure of respiratory organ, sepsis and heart disease as their dangerous complications ${ }^{51}$. Chronic hypertension, other cardiovascular co-morbidities, dyspnea, chest tightness and consciousness disorder have been 
observed to be more common in deceased patients compared to recovered patient $5^{52}$. The departed patient samples showed higher levels of the enzymes like creatinine, cardiac troponin $\mathrm{I}$, alanine aminotransferase, NT-proBNP, creatine kinase, D-dimer, aspartate aminotransferase and lactate dehydrogenase, and differed profiles of cytokine levels when compared to the patients, who were recovered from the disease (Fig. 1B).

COVID-19 patients with underlying cardiovascular conditions appear to face a higher risk of complications $s^{54}$. The American Heart Association has suggested that acute coronary events and strokes are common complications of viral infections. Influenza is linked to higher risk, while influenza vaccination in clinical trial reduced cardiovascular risk ${ }^{55}$. Individuals suffering from CVD are being advised by the American College of Cardiology for the influenza vaccination, in order to protect themselves from respiratory diseases that are related to the flu ${ }^{55,56}$. In China, CVD and hypertension were associated with an increased COVID-19 case fatality rate ${ }^{57}$.

Patients with cancer and/or CVD are at greater risk with worse outcomes with COVID-1958. C-reactive protein levels were recorded higher in COVID-19 than in recovered patients ${ }^{59}$. Amrane et $a{ } .{ }^{52}$ analyzed development of COVID-19 in anti-coagulated patients and reported that it might be associated with acute viral infection. Person suffering from COVID-19 and acute coronary syndrome are adopted in catheterization laboratory to check viral spread ${ }^{60,61}$. Heart diseases were found to be most prevalent co-morbidities in COVID-19 patients dying in Brazil25.

Dong et al. ${ }^{62}$ reported that end-stage heart failure in COVID-19 lead to an increased mortality rate and strong indication of SARS-CoV-2 induced cardiac injury. The Tongi Medical College performed screening for SARS-CoV-2 infection by nucleic acid and chest CT scan testing. COVID-19 patients in heart failure had prominent troponin I level, higher C-reactive protein ranges and brain natriuretic peptide and level of troponin I level increased before the death of the patient. The older age, poor general condition severe myocardial injury can be considered as the risk factors for COVID-19 infection ${ }^{51}$.

To understand the relation between COVID-19 and CVD, it is important to comprehend pathobiology of SARS-CoV-2. SARS-CoV and SARSCoV 2 entry involves the ACE2 receptor, which is expressed in nearly all body organs including on surfactant producing type 2 alveolar cells, ciliated and goblet cells of airways, the intestinal epithelium, cardiac cells, vascular endothelia, acini and islets of the pancreas ${ }^{63-65}$. Co-expression of ACE2 and Transmembrane Serine Protease 2 (TMPRSS2) in same cell type is required as the viral entry process needs to undergo priming of Spike (S) protein. TMPRSS2 play an important role in proteolytic cleavage of viral $S$ protein and in viral binding with ACE ${ }^{66}$. High expression of ACE2 is observed in pericytes. Pericytes are located outside endothelial cell of capillary and part of venules which might indicate for SARSCoV-2 infection of pericytes leading to increased thrombogenicity, and hypercoagulation seen in COVID-19 patients and a higher probability for acute coronary syndromes (ACS) ${ }^{67,68}$.

Moreover, myocardial ACE2 expression was significantly up-regulated in patients with heart failure with an increase of 3 fold compared to the patient with a healthy heart. This increase may give explanation of the higher infectivity of SARS-CoV- 2 and higher mortality in patients with heart disease ${ }^{69}$. These findings are relevant with another study which reported that the SARSCoV-2 can directly replicate in cardiomyocytes and pericytes, causing viral myocarditis ${ }^{70}$.

Higher cytokines levels are cardiotoxic and lead to intense myocardial injury ${ }^{70}$. Elevated levels of interleukin-1 (IL-1), chemoattractant proteins, interferon-gamma and inducible protein of interferon have been revealed in COVID-19 patients resulting in activation of helper $T$ cell response $^{71}$. The triggered helper $T$ cell initiates the differentiation of monocyte to macrophage, and then macrophage is recruited to the intimal layer of an artery. Modified lipid inside the plaque is enveloped by the macrophage to form foam cells. This foam cells altered the efferocytotic capacity (ability to clear apoptotic cells), which resulted in vast accumulation of cholesterol that leads to the formation of the necrotic core inside the lesion. Plaque with the necrotic core is unstable and prone to rupture ${ }^{72}$. This plaque rupture in the form of thromboembolism blocks the blood flow to the heart and responsible for ACS and cerebral ischaemic events ${ }^{73}$. This life-threatening condition 
may express the severity of COVID-19 infection, particularly concerning heart disease.

Zaim et al. ${ }^{74}$ suggested that COVID-19 can cause fatal outcomes in younger healthy individuals. Respiratory failure, severe hypoxia, septic shock, and multiple organ failure have been reported in younger individuals leading to mortality due to COVID-19. A recent study has suggested that myocardial injury is an important prognostic factor of COVID-1975. The tiny veins of the lungs have been found to expand at a higher ratio in individuals affected with COVID-1976.

One meta-analysis study reported varying proportions of the prevalence of cardiovascular co-morbidities among different CoVs-associated diseases (COVID-19, SARS and MERS cases) ${ }^{77}$. Zaman et al. $^{78}$ highlighted few of the salient issues with regards to practical approaches related to cardiovascular health care support and services for COVID-19 patients.

\section{COVID-19 and Hypertension}

The increased pressure in blood vessels has been characterized as hypertension, according to WHO. The higher incidence of hypertension might be due to immunodeficiency and longdrawn-out antiretroviral therapy, and conventional risk factors of older age, male gender, and high body mass index ${ }^{79}$. Essential hypertension (EH) is associated with cytomegalovirus (CMV) infection ${ }^{80}$, and gestational hypertension is associated with herpes simplex virus infection, during pregnancy ${ }^{81}$. Pulmonary arterial hypertension is associated with some viral infections viz., human immunodeficiency virus (HIV), human herpesvirus-8, hepatitis $B$, and $C^{82}$. However, in COVID-19, pulmonary hypertension is probably a significant factor for morbidity and mortality linked with $\mathrm{it}^{83}$. A study reported that the most common underlying risk factors in COVID-19 patients included hypertension, CVDs, diabetes, smoking, chronic obstructive pulmonary disease (COPD), malignancy, and chronic kidney disease $(\mathrm{CKD})^{84}$.

Hypertension is also one of the most common cardiovascular co-morbidities and appears to significantly elevate mortality risk in COVID-19 patients ${ }^{85}$. Lippi et al. ${ }^{86}$ reported that hypertension might be linked to a higher risk for severe and fatal outcome in COVID-19 affected persons. It has been reported that co- morbidities in COVID-19 include hypertension in nearly $21 \%$, diabetes in nearly $11 \%, C V D$ in about $7 \%$ patients, as per pooled data from Chinese studies ${ }^{87}$. Since these studies have not yet assessed the benefit to risk ratio in COVID-19 patients receiving rennin-angiotensin system blockers (RASB). These patients having co-morbidities connected to COVID-19 require special care as they give the highest risk of death cases. The exact mechanisms responsible for the poor prognosis in hypertensive COVID-19 patients need to be explored. However, one hypothesis is that the excessive activation of renin-angiotensin system (RAS) may promote the progression of lung injury in hypertensive COVID-19 patients via promotion of cytokine storm, smooth muscle cell contraction and vasoconstriction ${ }^{88}$. There is no solid evidence that proves the hypothesis suggesting that the use of ACE inhibitors (ACEI) or angiotensin receptor blockers (ARB) could be harmful in COVID-19 patients owing to increase in virus infectivity ${ }^{89}$.

ACE inhibitors / ARB in hypertensionCOVID-19 co-morbid patient results in reduced angiotensin 2 due to ACE inhibition and increased angiotensin 1-7 due to increased activity of ACE2. This results in drop in cytosolic $\mathrm{pH}$ producing more favorable environment for SARS-CoV-2 endocytosis ${ }^{90}$. Further angiotensin 1-7 acts on Mas receptors thus can cause increase in sympathetic activity in the brainstem ${ }^{91,92}$. This can also aggravate cardiovascular morbidity in such co-morbid patients ${ }^{92}$. Cardiovascular and renal diseases also complicate pathogenesis and disease severity of COVID-1936. Coronary artery disease and CKD further aggravate COVID-19 prognosis ${ }^{92}$. Though the utility of GLP-1Ra and SGLT-2i in such conditions may be well known but under co-morbid situations with COVID-19 their role in preserving cardiovascular and renal function need to be evaluated ${ }^{92,93}$. Some of them may have beneficial effects on oxidative-inflammatoryapoptotic pathway thus preventing oxidative stress, inflammation and apoptosis thereby attenuating vascular ischemia/reperfusion injury ${ }^{94}$. Another mechanism for increased severity and mortality is believed to be increased susceptibility of the COVID-19 co-morbid patients to infections of microbial pathogens including bacteria and fung ${ }^{95-97}$. 
Nevertheless, not having sturdy proof regarding advantage or harm, it is sensible to utilize ACE inhibitors and ARBs for therapeutic purposes ${ }^{87}$. There is dysfunction of reninangiotensin system (RAS) in COVID-19 patients. It is still unknown that RAS inhibitors like ACEls and ARBs render better disease outcomes. Severity of disease gets lowered as well as level of IL-6 is reported to be low in peripheral blood in patients administered ACEI or ARB therapy. Also, there is an increase in CD3 and CD8 T cell counts in the peripheral blood and decrease in reaching peak viral load using ACEI/ARB therapy as against giving antihypertensive drugs. This results in improving COVID-19 outcomes in patients suffering from hypertension, supporting the benefit of using ACEIs or $\mathrm{ARBs}^{98}$. Thus, treatment with ACEI/ARB is known to be linked to a lower mortality risk in comparison to non-ACEI/ARB therapy, among patients hospitalized with hypertension linked to COVID-1999.

Similarly, RAS inhibitors can modulate ACE2 mRNA expression and ACE2 function in tissues promoting SARS-CoV-2 proliferation and enhancing its infection capability ${ }^{100}$. Even though RAS is linked to lung damage and a high cardiovascular and renal risk using ACE2, it helps in SARS-CoV-2 entry into cells, as expressed in lung, cardiovascular system, kidney and other tissues, and thus these do not support a harmful impact of RAS blockers in SARS-CoV-2; therefore can be continued in constant patients facing the COVID-19 epidemic $^{101}$.

Renin hydrolyzes angiotensin into angiotensin I that is converted to angiotensin II by ACE. Angiotensin II effects on blood pressure and osmoregulation were mediated by angiotensin II receptor type I (ATR1). They are causing diverse effects comprising vasoconstriction and vascular remodeling. In healthy individuals, ATR 1 binds to ACE 2 to form a receptor complex. However, in a hypertensive patient, activation of ATR-1 by angiotensin II open the catalytic domain of ACE2, which hypothetically increases the virus entry to the cells via its spike protein ${ }^{102}$. The virus transmissibility, replication and disease severity depend on effectiveness of interaction between S-protein and ACE-2. Therefore, ACEIs and AT1R blockers aid in decreasing the viral load and attenuate the inflammatory response of COVID-19 infection $^{103,104}$.

ACE2 hydrolyzes angiotensin I into inactive angiotensin 1-9, angiotensin II into angiotensin 1-7 that further act on Mas receptor and cause a variety of effects, including cardiovascular defense, vasodilation, anti-proliferation, and anti-oxidative stress. Thus, homeostasis is maintained by functioning of ACE-Ang II-AT1R axis and ACE2-Ang1-7-MAS axis. The angiotensin I and angiotensin II levels, as ACE2 substrates, got remarkably increased, after ARB treatment which can persuade ACE2 expression and augment its activity. Some other studies stated that RAS blockers may potentiate SARS-CoV-2 infectivity and clinical course severity. Thus, it was opined to avoid RAS blockers for COVID-19 treatment.. More consistent ACE2 up-regulation was seen for ARBs, and ACE2 modulation by ACEls was more variable. Apart from this, the type and dosage of drugs used also play a key role ${ }^{99}$.

In hypertension, inflammatory dysregulation is another likely pathogenic association to COVID-19. Systemic IL-2, IL-6, IL7, granulocyte colony-stimulating factor, C-X-C motif chemokine 10 (CXCL10), chemokine (C-C motif) ligand 2 (CCL2) and TNF- $\alpha$ levels have been found to increase in COVID-19 patients. Proinflammatory cytokines are produced in greater amount (IL-17, IL-7, IL-6, IFN-C, TNF- $\alpha$ ) as a result of dysregulation of CD4 and CD8 cells during hypertension ${ }^{101}$.

\section{COVID-19 and Diabetes}

Diabetes has been considered as the risk factor that has been independently found to involve in the complications and mortality that occurred during SARS-CoV outbreak during the years $2002-2003^{105}$. Diabetes in the patients increased the risk of being hospitalized for approximately about three-fold and even to four-fold to be admitted in the intensive care unit in influenza A (H1N1) outbreak, which occurred during the year $2009^{106}$. The hypothesis of diabetogenic potential of COVID-19 has been explored by various workers ${ }^{107-109}$.

Co-morbid diabetes has been associated for a two-fold increase in risk of having a severe disease or even death in case of COVID-19 patients in China ${ }^{110}$. Diabetes prevalence was found to be 
approximately $14.5 \%$ in laboratory confirmed patients and linked with COVID-19 severe symptoms ${ }^{111}$. The study by Liu et al. ${ }^{112}$ differs from previous studies, profound impact of diabetes was not revealed on prognosis of COVID-19 patients although negatively impacted course of clinical disease. However this was attributed to lower sample size in this study ${ }^{112}$.

Although the current evidence suggests that individuals with diabetes are affected with a severe type of COVID-19, the mechanism associated with the difference in pathology is not clear ${ }^{111}$. Therefore, further knowledge on the interaction between diabetes and COVID-19 can help us to develop suitable therapeutic strategies for reducing mortality. It has been speculated that blood glucose and body mass index might play a crucial role in poor prognosis linked to COVID-19 patients having diabetes ${ }^{113}$. Type 1 diabetes patients are at risks of severe COVID-19. Infection of SARS-CoV-2 may worsen diabetes via precipitating acute metabolic complications by negatively affecting $\beta$-cell function, which could lead to diabetic ketoacidosis, hyperglycaemia and new-onset diabetes ${ }^{16}$.

Another outbreak of CoV is caused by MERS-CoV, during the year 2012. The diabetic patients have been found to have higher risk during this outbreak too. Approximately, about $50 \%$ of the people with the critical illness were found to have diabetes ${ }^{114}$. Dipeptidyl peptidase-4 (DPP-4) is a transmembrane glycoprotein, type II that is expressed in many cells and tissues including immune cells of the body. This glycoprotein has been found to have a critical role in metabolism of glucose as well as insulin. The glucagon-like peptide (GLP-1), as well as a glucose-dependent insulinotropic polypeptide, may be degraded by DPP-4 that results in the declined secretion of insulin and abnormal metabolism in the visceral adipose tissue ${ }^{115}$. The postprandial glucose is regulated through the GLP-1 degradation by the DPP-4. The interaction between DPP-4 and coronavirus has been studied by using the mouse model, in which the results showed that the mouse was susceptible to MERS-CoV${ }^{116}$. In the case of COVID-19, the DPP-4 has been found to reduce the risk of respiratory complications that is related to diabetes. A study by Akbar ${ }^{117}$, has suggested that the diabetic patients with the elevated glycemic levels were found to have a higher risk at the rate of $60 \%$ for being hospitalized during the pneumonia-related infections. This has been observed due to the decline in innate and humoral immune responses in diabetic patients ${ }^{87,117}$.

Diabetes could be a significant risk factor leading to hospitalization and increased mortality of the COVID-19 patients. The 22 out of 32 deceased COVID-19 patients were observed to have diabetes as their co-morbidity ${ }^{103}$. Few studies have reported that about $12 \%$ to $16.2 \%$ of hospitalized patients due to COVID-19 have been observed to suffer from diabetes ${ }^{99,104}$. The severity of the patients increases for two folds in case of individuals with diabetes ${ }^{104}$. A clinical survey conducted on the confirmed COVID-19 patients in China and the reports suggested that diabetes has been observed to be the most common co-morbidity in about $16.2 \%$ of the severe cases. A potential mechanism that might enhance susceptibility and severity of COVID-19 in diabetic patient has been discussed in several studies. Jing Liang et al. ${ }^{118}$ investigated the laboratory findings of SARS-CoV-2 patients having type 2 diabetes mellitus. Findings indicated that the affected patients exhibited decreased levels of lymphocytes, uric acid, albumin, and body mass index along with an increase in C-reactive protein levels. The decreased levels of uric acid, albumin, and body mass index can be linked to the oxidative stress response and nutritional consumption ${ }^{118}$.

Increased ACE 2 in lung, kidney, heart and pancreas has been seen in diabetic mice ${ }^{119}$. An elevated level of furin, a cellular protease which cleaves S1 and S2 domain of viral spike protein, is also presented in diabetes mellitus patients. The increase of ACE 2 receptor and furin level might facilitate the viral entry resulting in higher binding affinity, which leads to an increase in the susceptibility of COVID-19 inpatient with diabetes $^{119-121}$.

A few studies have provided information regarding diabetes and its positive association with worsening COVID-19. The diabetic patients are easily susceptible to the COVID-19 since the body mechanisms of diabetes affected individuals are not more efficient to clear the viral entry with the weakened immune cell functions and high 
susceptibility to the inflammation ${ }^{115,122}$. Recently, a study showed that SARS-CoV-2 clearance was prolonged in diabetic patients ${ }^{123}$. Delayed recruitment of neutrophils and macrophages might impact the viral clearance ${ }^{123}$.

Deterioration of adaptive immunity in diabetic patients is marked by delayed activation of Th1 cell-mediated immunity and dysregulation of inflammatory markers. Excessive release of inflammatory biomarkers (C-reactive protein, IL-6, TNF- $\alpha$ ) may lead to cytokine storm that can result

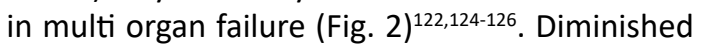
$T$ cell function is also consistent with the finding in severe COVID-19 patient where a significant decrease of CD4+ and CD8+, an augmentation of proinflammatory CCR6+ Th17 in CD4 T cells, high concentration of cytotoxic granules in CD8+ was observed in peripheral blood. These factors may play a role in severe immune injury in COVID-19 patient with DM as co-morbidity 127,128 .

Studies have suggested that the patients with diabetes have been found to have a lower recovery rate in SARS-CoV infections, which is the previous outbreak caused by a novel $\mathrm{CoV}^{129,130}$. Studies done in Wuhan have reported that COVID-19 treatment has resulted in the worsening of hyperglycaemic condition in around
$10 \%$ of the individuals with diabetes. The clinical consequences led to the increase in cardiovascular abnormalities that resulted in severe illness of COVID-19 patients with diabetes ${ }^{93,129,131}$. Studies have reported prevalence of CVD, hypertension and diabetes in severely affected SARS-CoV-2 infected patients as $7 \%, 21 \%$ and $11 \%$, respectively ${ }^{103}$. A bidirectional connection has been recently reported between diabetes and COVID-19, as a phenomenon of new-onset diabetes and severe metabolic problems in pre-existing diabetes like changes in glucose metabolism, diabetic ketoacidosis and hyperosmolarity requiring very high insulin administration. A hypothesis of a potent diabetogenic consequence of SARSCoV-2 has been suggested, which need further explorative studies to further reveal novel modes of disease $\mathrm{e}^{132}$. Pancreatic damage can occur in COVID-19 and stress hyperglycaemia in patients that may require insulin ${ }^{133}$.

Diabetes patients getting COVID-19 have severe disease course and higher mortality ${ }^{134}$. Disease severity is due to compromised immune response, elevated inflammatory response and hypercoagulable state ${ }^{134}$. Management of diabetic patients is also affected in COVID-1992. Administering ACE inhibitors and ARB in such
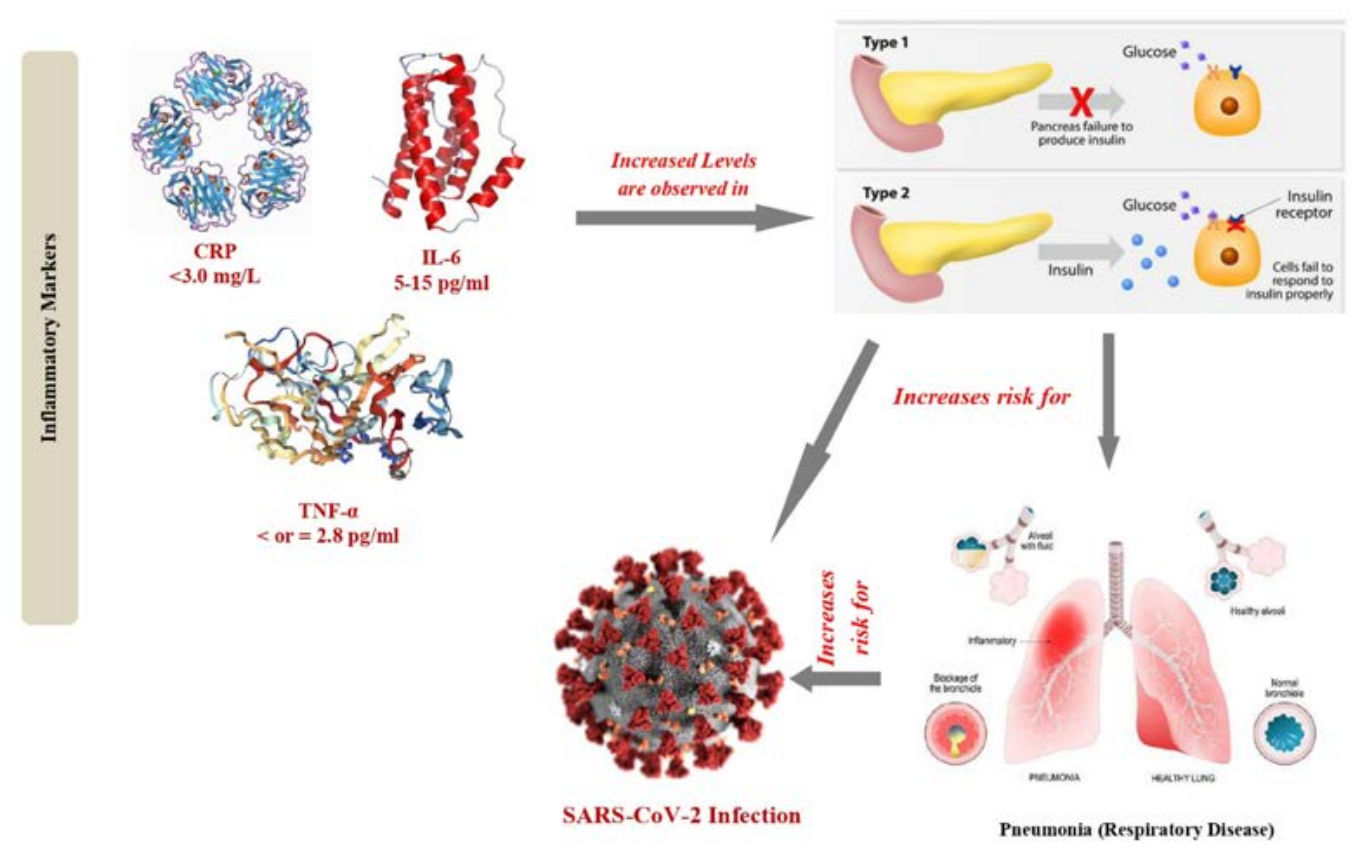

Fig.2. Diabetes and the associated risks 
patients has raised some concerns including effects on pulmonary functions ${ }^{134}$. As ACE2R is SARSCoV-2 target, hence anti-diabetic drugs inducing expression of such receptors can predispose to infection besides increasing severity ${ }^{92}$. SodiumGlucose-Transporter-2 inhibitors (SGLT-2i), Glucagon-Like-Peptide-1 Receptor Agonists (GLP-1RAs), pioglitazone and even insulin could persuade an over-expression of ACE2 receptor ${ }^{135}$, thus increase risk and aggravate severity of COVID-1992. Dipeptidyl Peptidase 4 (DPP4) receptors are also exploited by coronaviruses ${ }^{7}$, hence DPP4 inhibitors and GLP-1 receptor analogues which are having role in diabetes therapy need to be investigated for concomitant therapy of diabetic COVID-19 patients ${ }^{92,136}$. Similarly, antihyoerglycemic effects of hydroxychloroquine along with anti-inflammatory and antiviral (anti-SARS-CoV-2) effects also favour its use in COVID-19 patients with diabetes ${ }^{136,137}$. Movement restrictions can aggravate emergency situations of co-morbid patients hence telemedicine can be helpful ${ }^{134}$. Future studies should focus on individual, regional, ethnic variations in prevalence and course of disease ${ }^{134}$.

\section{CONCLUSION AND FUTURE PROSPECTS}

The literature survey, including the available recent studies, has found to support the statement, that the co-morbidities increases the susceptibility, risk of mortality and decreases survival rate in COVID-19 patients by worsening the clinical outcomes in terms of higher disease severity. The individuals without co-morbidities are being found to have higher chances of recovery rate, and the rate of mortality has been found less. Hence, we can conclude that heart disease, hypertension and diabetes are positively associated with worsening of disease severity during SARS-CoV-2 infection. In such scenario, patients suffering from different co-morbidities require prioritising attention and critical health care support in managing their diseases conditions during COVID-19 pandemic which could aid in saving their lives to some extent. In addition, special prevention and control strategies are required to be adopted strictly to minimise risk of SARS-CoV-2 transmission to uninfected population at risk especially patients suffering with different co-morbidities to avoid complicating disease conditions.

\section{ACKNOWLEDGMENTS}

The authors acknowledge their Institutes and Universities.

\section{CONFLICT OF INTEREST}

The authors declares that there is no conflict of interest.

\section{AUTHORS' CONTRIBUTION}

All authors listed have made a substantial, direct and intellectual contribution to the work, and approved it for publication.

\section{FUNDING}

None.

\section{ETHICS STATEMENT}

Not Applicable.

\section{DATA AVAILABILITY}

All datasets generated or analyzed during this study are included in the manuscript and/or the Supplementary Files.

\section{REFERENCES}

1. Harapan H, Itoh N, Yufika A, et al. Coronavirus disease 2019 (COVID-19): A literature review. J Infect Public Health. 2020;13(5):667-673. doi: 10.1016/j. jiph.2020.03.019

2. Ahmad T, Haroon, Baig M, Hui J. Coronavirus Disease 2019 (COVID-19) Pandemic and Economic Impact. Pak J Med Sci. 2020;36(COVID19-S4):S73-S78. doi: 10.12669/pjms.36.COVID19-S4.2638

3. Ayittey FK, Ayittey MK, Chiwero NB, Kamasah JS, Dzuvor C. Economic Impacts of Wuhan 2019-nCoV on China and the World. J Med Virol. 2020;92(5):473-475. doi: 10.1002/jmv.25706

4. Nicola M, Alsafi Z, Sohrabi C, et al. The socio-economic implications of the coronavirus pandemic (COVID-19): A review. Int J Surg. 2020; 78(2020):185-193. doi: 10.1016/j.ijsu.2020.04.018

5. Ciotti $M$, Ciccozzi M, Terrinoni A, Jiang WC, Wang CB, Bernardini S. The COVID-19 pandemic. Crit Rev Clin Lab Sci. 2020;1-24. doi: 10.1080/10408363.2020.1783198

6. Dhama K, Saminathan M, Jacob SS, et al. Effect of immunomodulation and immunomodulatory agents on health with some bioactive principles, modes of action and potent biomedical applications. Int J Pharmacol. 2015;11(4):253-290. doi: 10.3923/ 
ijp.2015.253.290

7. Dhama K, Khan S, Tiwari R, et al. Coronavirus Disease 2019-COVID-19. Clin Microbiol Rev. 2020a;33(4):e00028-20. doi: 10.1128/CMR.00028-20

8. Golonka RM, Saha P, Yeoh BS, et al. Harnessing innate immunity to eliminate SARS-CoV-2 and ameliorate COVID-19 disease. Physiol Genmics. 2020;52(5):217221. 10.1152/physiolgenomics.00033.2020

9. Jayawardena $R$, Sooriyaarachchi $P$, Chourdakis $M$, Jeewandara $C$, Ranasinghe $P$. Enhancing immunity in viral infections, with special emphasis on COVID-19: A review. Diabetes Metab Syndr. 2020;14(4):367-382. doi: 10.1016/j.dsx.2020.04.015

10. Keam S, Megawati D, Patel SK, Tiwari R, Dhama K, Harapan H. Immunopathology and immunotherapeutic strategies in severe acute respiratory syndrome coronavirus 2 infection. Rev Med Virol. 2020. doi: $10.1002 / \mathrm{rmv} .2123$

11. Keni R, Alexander A, Nayak PG, Mudgal J, Nandakumar K (2020) COVID-19: Emergence, Spread, Possible Treatments, and Global Burden. Front Public Health. 2020 May 28;8:216. doi: 10.3389/fpubh.2020.00216

12. Malik YS, Kumar N, Sircar S, et al. Coronavirus Disease Pandemic (COVID-19): Challenges and a Global Perspective. Pathogens. 2020b;9(7):E519. doi: 10.3390/pathogens9070519

13. Sharun K, Tiwari R, Iqbal Yatoo M, et al. Antibodybased immunotherapeutics and use of convalescent plasma to counter COVID-19: advances and prospects. Expert Opin Biol Ther. 2020 Aug 3;1-14. doi: 10.1080/14712598.2020.1796963

14. Yatoo MI, Hamid Z, Parray OR, et al. COVID-19 Recent advancements in identifying novel vaccine candidates and current status of upcoming SARS-CoV-2 vaccines. Hum Vaccin Immunother. 2020;1-14. doi: 10.1080/21645515.2020.1788310

15. Jin J-M, Bai P, He W, et al. Gender differences in patients with COVID-19: Focus on severity and mortality. Frontiers in Public Health. 2020; 8:152. doi: 10.3389/ fpubh.2020.00152

16. Apicella M, Campopiano MC, Mantuano M, Mazoni L, Coppelli A, Del Prato S. COVID-19 in people with diabetes: understanding the reasons for worse outcomes. Lancet Diabetes Endocrinol. 2020;S2213-8587(20):30238-2. doi: 10.1016/S22138587(20)30238-2

17. Baradaran A, Ebrahimzadeh $\mathrm{MH}$, Baradaran $\mathrm{A}$, Kachooei AR. Prevalence of Comorbidities in COVID-19 Patients: A Systematic Review and Meta-Analysis. Arch Bone Jt Surg. 2020;8(Suppl 1):247-255. doi: 10.22038/ abjs.2020.47754.2346

18. Weis N, Thorsteinsson K, Martinussen C, Madsbad $\mathrm{S}$. The endocrine and metabolic link between COVID-19, diabetes and obesity. Ugeskr Laeger. 2020;182(29):V05200381

19. Qiu P, Zhou Y, Wang F, et al. Clinical characteristics, laboratory outcome characteristics, comorbidities, and complications of related COVID-19 deceased: a systematic review and meta-analysis. Aging Clin Exp Res. 2020. doi: 10.1007/s40520-020-01664-3

20. Lu QB, Jiang WL, Zhang $X$, et al. Comorbidities for fatal outcome among the COVID-19 patients: a hospital- based case-control study. J Infect. 2020;S01634453(20):30507-7. doi: 10.1016/j.jinf.2020.07.026

21. Wang J, Zhu L, Liu L, et al. Overweight and obesity are risks factors of severe illness in patients with COVID-19. Obesity (Silver Spring). 2020. doi: 10.1002/oby.22979

22. Richardson S, Hirsch JS, Narasimhan M, et al. Presenting Characteristics, Comorbidities, and Outcomes Among 5700 Patients Hospitalized With COVID-19 in the New York City Area. JAMA. 2020;323(20):2052-2059. doi: 10.1001/jama.2020.6775

23. Wu Z, McGoogan JM. Characteristics of and Important Lessons From the Coronavirus Disease 2019 (COVID-19) Outbreak in China: Summary of a Report of 72314 Cases From the Chinese Center for Disease Control and Prevention. JAMA. 2020;323(13):1239-1242. doi: 10.1001/jama.2020.2648

24. Yang J, Zheng $Y$, Gou X, et al. Prevalence of comorbidities and its effects in patients infected with SARS-CoV-2: a systematic review and meta-analysis. Int J Infect Dis. 2020;94:91-95. doi: 10.1016/j.ijid.2020.03.017

25. Pachiega J, Afonso AJDS, Sinhorin GT, et al. Chronic heart diseases as the most prevalent comorbidities among deaths by COVID-19 in Brazil. Rev Inst Med Trop Sao Paulo. 2020;62:e45. doi: 10.1590/S16789946202062045

26. Momtazmanesh S, Shobeiri P, Hanaei S, MahmoudElsayed H, Dalvi B, Malakan Rad E. Cardiovascular disease in COVID-19: a systematic review and metaanalysis of 10,898 patients and proposal of a triage risk stratification tool. Egypt Heart J. 2020;72(1):41. doi: 10.1186/s43044-020-00075-z

27. Guzik TJ, Mohiddin SA, Dimarco A, et al. COVID-19 and the cardiovascular system: implications for risk assessment, diagnosis, and treatment options. Cardiovasc Res. 2020;116(10):1666-1687. doi: 10.1093/cvr/cvaa106

28. Ruan Q, Yang K, Wang W, Jiang L, Song J. Clinical predictors of mortality due to COVID-19 based on an analysis of data of 150 patients from Wuhan, China. Intensive Care Med. 2020;46(5):846-848. doi: 10.1007/ s00134-020-05991-x

29. Adamo M, Lombardi CM, Metra M. June 2020 at a glance: focus on COVID-19, quality of life and comorbidities. Eur J Heart Fail. 2020;22(6):917-918. doi: 10.1002/ejhf.1515

30. Bromage DI, Cannata A, Rind IA, Gregorio C, Piper $S$, Shah AM, McDonagh TA. The impact of COVID-19 on heart failure hospitalization and management: report from a Heart Failure Unit in London during the peak of the pandemic. Eur J Heart Fail. 2020;22:978-984. doi: 10.1002/ejhf.1925

31. Tomasoni D, Italia L, Adamo M, et al. COVID-19 and heart failure: from infection to inflammation and angiotensin II stimulation. Searching for evidence from a new disease. Eur J Heart Fail. 2020;22(6):957-966. doi: 10.1002/ejhf.1871

32. Zhang Y, Stewart Coats AJ, Zheng Z, et al. Management of heart failure patients with COVID-19: a joint position paper of the Chinese Heart Failure Association \& National Heart Failure Committee and the Heart Failure Association of the European Society of Cardiology. Eur J Heart Fail. 2020;22:941-956. doi: 


\subsection{2/ejhf.1915}

33. Long B, Brady WJ, Koyfman A, Gottlieb M Cardiovascular complications in COVID-19. Am J Emerg Med. 2020;38(7):1504-1507. doi: 10.1016/j. ajem.2020.04.048

34. Madjid M, Safavi-Naeini P, Solomon SD, Vardeny O: Potential Effects of Coronaviruses on the Cardiovascular System: A Review. JAMA Cardiol. 2020;5(7):831-840. doi: 10.1001/jamacardio.2020.1286

35. Azevedo RB, Botelho BG, Hollanda JVG, et al. Covid-19 and the cardiovascular system: a comprehensive review. J Hum Hypertens. 2020:1-8. doi: 10.1038/ s41371-020-0387-4

36. Dhama K, Patel SK, Pathak M, et al. An update on SARS-CoV-2/COVID-19 with particular reference to its clinical pathology, pathogenesis, immunopathology and mitigation strategies. Travel Med Infect Dis. 2020b; 101755. doi: 10.1016/j.tmaid.2020.101755

37. Bansal M. Cardiovascular disease and COVID-19. Diabetes Metab Syndr. 2020;14(3):247-250. doi: 10.1016/j.dsx.2020.03.013

38. Xiong TY, Redwood S, Prendergast B, Chen M. Coronaviruses and the cardiovascular system: acute and long-term implications. Eur Heart J. 2020;41(19):1798-1800. doi: 10.1093/eurheartj/ ehaa231

39. Zhou F, Yu T, Du R, et al. Clinical course and risk factors for mortality of adult inpatients with COVID-19 in Wuhan, China: a retrospective cohort study. Lancet. 2020;395(10229):1054-1062. doi: 10.1016/S01406736(20)30566-3

40. Chen D, Li X, Song Q, et al. Assessment of Hypokalemia and Clinical Characteristics in Patients With Coronavirus Disease 2019 in Wenzhou, China. JAMA Netw Open. 2020a;3(6):e2011122. doi: 10.1001/ jamanetworkopen.2020.11122

41. Yao XH, Li TY, He ZC, et al. [A pathological report of three COVID-19 cases by minimal invasive autopsies]. Zhonghua Bing Li Xue Za Zhi. 2020;49(5):411-417. Chinese. doi: 10.3760/ cma.j.cn112151-20200312-00193.

42. Long A, Grimaldo F. Spontaneous hemopneumothorax in a patient with COVID-19: A case report. Am J Emerg Med. 2020. doi: 10.1016/j.ajem.2020.07.065.

43. Siripanthong B, Nazarian S, Muser D, et al. Recognizing COVID-19-related myocarditis: The possible pathophysiology and proposed guideline for diagnosis and management. Heart Rhythm. 2020;S15475271(20)30422-7. doi: 10.1016/j.hrthm.2020.05.001

44. Liu PP, Blet A, Smyth D, Li H: The Science Underlying COVID-19: Implications for the Cardiovascular System. Circulation. 2020a;142(1):68-78. doi: 10.1161/ CIRCULATIONAHA.120.047549

45. Zeng JH, Liu YX, Yuan J, et al. First case of COVID-19 complicated with fulminant myocarditis: a case report and insights. Infection. 2020 Apr 10:1-5. doi: 10.1007/ s15010-020-01424-5.

46. Babapoor-Farrokhran S, Gill D, Walker J, Rasekhi RT, Bozorgnia B, Amanullah A. Myocardial injury and COVID-19: Possible mechanisms. Life Sci. 2020;253:117723. doi: 10.1016/j.Ifs.2020.117723. Epub 2020 Apr 28. PMID: 32360126; PMCID:

\section{PMC7194533.}

47. Rizzo P, Sega FVD, Fortini F, Marracino L, Rapezzi C, Ferrari R. COVID-19 in the heart and the lungs: could we "Notch" the inflammatory storm? Basic Res Cardiol. 2020;115(3):31. doi: 10.1007/s00395-020-0791-5

48. Jean SS, Lee PI, Hsueh PR. Treatment options for COVID-19: The reality and challenges. J Microbiol Immunol Infect. 2020;53(3):436-443

49. Zheng YY, Ma YT, Zhang JY, Xie X. COVID-19 and the cardiovascular system. Nat Rev Cardiol. 2020;17(5):259-260. doi: 10.1038/s41569-020-0360-5

50. Hulot JS. COVID-19 in patients with cardiovascular diseases. Arch Cardiovasc Dis. 2020, 113(4):225-226. doi: 10.1016/j.acvd.2020.03.009

51. Guan WJ, Liang WH, Zhao Y, et al. Comorbidity and its impact on 1590 patients with COVID-19 in China: a nationwide analysis. Eur Respir J. 2020;55(5): 2000547. doi: 10.1183/13993003.00547-2020

52. Amrane S, Tissot-Dupont H, Doudier B, et al. Rapid viral diagnosis and ambulatory management of suspected COVID-19 cases presenting at the infectious diseases referral hospital in Marseille, France, - January $31^{\text {st }}$ to March $1^{\text {st }}, 2020$ : A respiratory virus snapshot. Travel Med Infect Dis. 2020:101632. doi: 10.1016/j. tmaid.2020.101632

53. Huang $\mathrm{C}$, Wang $\mathrm{Y}$, Li X, et al. Clinical features of patients infected with 2019 novel coronavirus in Wuhan, China. Lancet. 2020;395(10223):497-506. doi: 10.1016/ S0140-6736(20)30183-5

54. Elkind MSV, Harrington RA, Benjamin IJ. The Role of the American Heart Association in the Global COVID-19 Pandemic. Circulation. 2020;141(15):e743-e745. doi: 10.1161/CIRCULATIONAHA.120.046749

55. Michot JM, Albiges L, Chaput N, et al. Tocilizumab, an anti-IL-6 receptor antibody, to treat COVID19-related respiratory failure: a case report. Ann Oncol. 2020;31(7):961-964. doi: 10.1016/j. annonc.2020.03.300

56. Ramadan N, Shaib H. Middle East respiratory syndrome coronavirus (MERS-CoV): A review. Germs. 2019;9(1):35-42. doi: 10.18683/germs.2019.1155

57. Leiva Sisnieguez CE, Espeche WG, Salazar MR. Arterial hypertension and the risk of severity and mortality of COVID-19. Eur Respir J. 2020;55(6): 2001148. doi: 10.1183/13993003.01148-2020

58. Asokan I, Rabadia SV, Yang EH. The COVID-19 Pandemic and its Impact on the Cardio-Oncology Population. Curr Oncol Rep. 2020;22(6):60. doi: 10.1007/s11912-02000957-0

59. Luo X, Zhou W, Yan X, et al. Prognostic value of C-reactive protein in patients with COVID-19. medRxiv. 2020. doi: 10.1101/2020.03.21.20040360

60. de Luca D. Managing neonates with respiratory failure due to SARS-CoV-2. Lancet Child Adolesc Health. 2020;4(4):e8. doi: 10.1016/S2352-4642(20)30073-0

61. Bettari L, Pero G, Maiandi C, et al. Exploring Personal Protection During High-Risk PCl in a COVID-19 Patient: Impella CP Mechanical Support During ULMCA Bifurcation Stenting. JACC Case Rep. 2020;2(9):12791283. doi: $10.1016 /$ j.jaccas.2020.03.006

62. Dong N, Cai J, Zhou Y, Liu J, Li F. End-Stage Heart Failure With COVID-19: Strong Evidence of Myocardial Injury 
by 2019-nCoV. JACC Heart Fail. 2020;8(6):515-517. doi: 10.1016/j.jchf.2020.04.001

63. Hamming I, Timens W, Bulthuis MLC, Lely AT, Navis GJ, van Goor H. Tissue distribution of ACE2 protein, the functional receptor for SARS coronavirus. A first step in understanding SARS pathogenesis. The Journal of Pathology. 2004;203(2):631-637. doi: 10.1002/ path.1570

64. Sims AC, Baric RS, Yount B, Burkett SE, Collins PL, Pickles RJ. Severe Acute Respiratory Syndrome Coronavirus Infection of Human Ciliated Airway Epithelia: Role of Ciliated Cells in Viral Spread in the Conducting Airways of the Lungs. J Virol. 2005;79(24):15511-15524. doi: 10.1128/JVI.79.24.15511-15524.2005

65. Batlle D, Jose Soler M, Ye M. ACE2 and Diabetes: ACE of ACEs? Diabetes. 2010;59(12):2994-2996. doi: 10.2337/ db10-1205

66. Hoffmann M, Kleine-Weber H, Schroeder S, et al. SARSCoV-2 Cell Entry Depends on ACE2 and TMPRSS2 and Is Blocked by a Clinically Proven Protease Inhibitor. Cell. 2020;181(2):271-280 e278. doi: 10.1016/j. cell.2020.02.052

67. Shiraki K, Daikoku T. Favipiravir, an anti-influenza drug against life-threatening RNA virus infections. Pharmacol Ther. 2020;209:107512. doi: 10.1016/j. pharmthera.2020.107512

68. He L, Mae MA, Sun Y, et al. Pericyte-specific vascular expression of SARS-CoV-2 receptor ACE2 - implications for microvascular inflammation and hypercoagulopathy in COVID-19 patients. bioRxiv. 2020:2020.2005.2011.088500

69. Chen L, Li X, Chen M, Feng Y, Xiong C. The ACE2 expression in human heart indicates new potential mechanism of heart injury among patients infected with SARS-CoV-2. Cardiovascular Research. 2020b;116(6):1097-1100. doi: 10.1093/cvr/cvaa078

70. Hendren NS, Drazner MH, Bozkurt B, Cooper LT, Jr. Description and Proposed Management of the Acute COVID-19 Cardiovascular Syndrome. Circulation. 2020;141(23):1903-1914. doi: 10.1161/ CIRCULATIONAHA.120.047349

71. Costela-Ruiz VJ, Illescas-Montes R, Puerta-Puerta JM, Ruiz C, Melguizo-Rodriguez L. SARS-CoV-2 infection: The role of cytokines in COVID-19 disease. Cytokine Growth Factor Rev. 2020;S1359-6101(20)30109-X. doi: 10.1016/j.cytogfr.2020.06.001

72. Gregersen I, Halvorsen B. Inflammatory Mechanisms in Atherosclerosis. In. edn. 2017. doi: 10.5772/ intechopen.72222

73. Bentzon Jacob F, Otsuka F, Virmani R, Falk E. Mechanisms of plaque formation and rupture. Circulation Research. 2014;114(12):1852-1866. doi: 10.1161/CIRCRESAHA.114.302721

74. Zaim S, Chong JH, Sankaranarayanan V, Harky A. COVID-19 and Multiorgan Response. Curr Probl Cardiol. 2020;45(8):100618. doi: 10.1016/j. cpcardiol.2020.100618

75. Udwadia ZF, Tripathi AR, Nanda VJ, Joshi SR. Prognostic Factors for Adverse Outcomes in COVID-19 Infection. J Assoc Physicians India. 2020;68(7):62-66. PMID: 32602683

76. Paramasivam A, Priyadharsini JV, Raghunandhakumar
S, Elumalai P. A novel COVID-19 and its effects on cardiovascular disease. Hypertens Res. 2020;43(7):729730. doi: 10.1038/s41440-020-0461-x

77. Liu Y, Wu S, Qin M, Jiang W, Liu X. The prevalence of cardiovascular comorbidities in COVID-19, SARS and MERS: pooled analysis of published data. J Am Heart Assoc. 2020b:e016812. doi: 10.1161/JAHA.120.016812

78. Zaman S, Maclsaac Al, Jennings GL, et al. Cardiovascular disease and COVID-19: Australian and New Zealand consensus statement. Med J Aust. 2020. doi: 10.5694/ mja2.50714

79. Sanidas E, Papadopoulos DP, Velliou M, Tsioufis K, Barbetseas J, Papademetriou V. Human Immunodeficiency Virus Infection And Hypertension. Is There a Connection? Am J Hypertens. 2018;31(4):389393. doi: $10.1093 / a j h / h p x 208$

80. Hui J, Qu YY, Tang N, et al. Association of cytomegalovirus infection with hypertension risk: a meta-analysis. Wien Klin Wochenschr. 2016;128(15-16):586-591. 0.1007/ s00508-016-0977-x

81. Shi L, Wu Y. HSV infection is associated with gestational hypertension: results from the US National inpatient sample. Journal of Investigative Medicine. 2018;66(5):1-5. doi: 10.1136/jim-2017-000687

82. Cool CD, Voelkel NF, Bull T. Viral infection and pulmonary hypertension: is there an association? Expert Rev Respir Med. 2011;5(2):207-216. doi: 10.1586/ers.11.17

83. Ryan JJ, Melendres-Groves L, Zamanian RT, et al. Care of patients with pulmonary arterial hypertension during the coronavirus (COVID-19) pandemic. Pulm Circ. 2020;10(2):2045894020920153. doi: 10.1177/2045894020920153

84. Emami A, Javanmardi F, Pirbonyeh N, Akbari A. Prevalence of Underlying Diseases in Hospitalized Patients with COVID-19: a Systematic Review and Meta-Analysis. Arch Acad Emerg Med. 2020;8(1):e35. PMC7096724

85. Zuin M, Rigatelli G, Zuliani G, Rigatelli A, Mazza A, Roncon L. Arterial hypertension and risk of death in patients with COVID-19 infection: Systematic review and meta-analysis. J Infect. 2020;81(1):e84-e86. doi: 10.1016/j.jinf.2020.03.059

86. Lippi G, Wong J, Henry BM. Hypertension and its severity or mortality in Coronavirus Disease 2019 (COVID-19): a pooled analysis. Pol Arch Intern Med. 2020;130(4):304-309. doi: 10.20452/pamw.15272

87. Singh AK, Gupta R, Misra A: Comorbidities in COVID-19: Outcomes in hypertensive cohort and controversies with renin angiotensin system blockers. Diabetes Metab Syndr. 2020;14(4):283-287. doi: 10.1016/j. dsx.2020.03.016

88. Sommerstein R, Kochen MM, Messerli FH, Grani C. Coronavirus Disease 2019 (COVID-19): Do AngiotensinConverting Enzyme Inhibitors/Angiotensin Receptor Blockers Have a Biphasic Effect? J Am Heart Assoc. 2020;9(7):e016509. doi: 10.1161/JAHA.120.016509

89. Teixeira R, Santos M, Gil V. COVID-19 and cardiovascular comorbidities: An update. Rev Port Cardiol. 2020:S0870-2551(20)30281-X. doi: 10.1016/j. repc.2020.06.013

90. Cure E, Cumhur Cure M. Comment on "organ- 
protective effect of angiotensin-converting Enzyme 2 and its effect on the prognosis of COVID-19". J Med Virol. 2020. doi: 10.1002/jmv.25848

91. Bilodeau MS, Leiter JC. Angiotensin 1-7 in the rostroventrolateral medulla increases blood pressure and splanchnic sympathetic nerve activity in anesthetized rats. Respir Physiol Neurobiol. 2018;247:103-111. doi: 10.1016/j.resp.2017.10.003

92. Ceriello A, Stoian AP, Rizzo M. COVID-19 and diabetes management: What should be considered? Diabetes Res Clin Pract. 2020;163:108151. doi: 10.1016/j. diabres.2020.108151

93. Zhou J, Tan J. Diabetes patients with COVID-19 need better blood glucose management in Wuhan, China. Metabolism. 2020;107:154216. doi: 10.1016/j. metabol.2020.154216

94. Amin EF, Rifaai RA, Abdel-Latif RG. Empagliflozin attenuates transient cerebral ischemia/reperfusion injury in hyperglycemic rats via repressing oxidativeinflammatory-apoptotic pathway. Fundam Clin Pharmacol. 2020;10.1111/fcp.12548. doi: 10.1111/ fcp. 12548

95. Fang L, Karakiulakis G, Roth M. Are patients with hypertension and diabetes mellitus at increased risk for COVID-19 infection? Lancet Respir Med. 2020;8(4):e21. doi: 10.1016/S2213-2600(20)301168. Epub 2020 Mar 11. Erratum in: Lancet Respir Med. 2020 Jun;8(6):e54.

96. Hughes S, Troise O, Donaldson H, Mughal N, Moore LSP. Bacterial and fungal coinfection among hospitalized patients with COVID-19: a retrospective cohort study in a UK secondary-care setting. Clin Microbiol Infect. 2020;S1198-743X(20)30369-4. doi: 10.1016/j. cmi.2020.06.025

97. Langford BJ, So M, Raybardhan S, et al. Bacterial coinfection and secondary infection in patients with COVID-19: a living rapid review and meta-analysis. Clin Microbiol Infect. 2020;\$1198-743X(20)30423-7. doi: 10.1016/j.cmi.2020.07.016

98. Meng J, Xiao G, Zhang J, et al. Renin-angiotensin system inhibitors improve the clinical outcomes of COVID-19 patients with hypertension. Emerg Microbes Infect. 2020;9(1):757-760. doi: 10.1080/22221751.2020.1746200

99. Zhang JJ, Dong X, Cao YY, et al. Clinical characteristics of 140 patients infected with SARS-CoV-2 in Wuhan, China. Allergy. 2020;75(7):1730-1741. doi: 10.1111/ all.14238

100. Li G, Hu R, Zhang X. Antihypertensive treatment with ACEI/ARB of patients with COVID-19 complicated by hypertension. Hypertens Res. 2020;43(6):588-590. doi: 10.1038/s41440-020-0433-1

101. Kreutz R, Algharably EAE, Azizi M, et al. Hypertension, the renin-angiotensin system, and the risk of lower respiratory tract infections and lung injury: implications for COVID-19. Cardiovasc Res. 2020;116(10):16881699. doi: $10.1093 /$ cvr/cvaa097

102. Chowdhury R, Maranas C. Biophysical characterization of the SARS-CoV2 spike protein binding with the ACE2 receptor explains increased COVID-19 pathogenesis. 2020. doi: 10.1101/2020.03.30.015891

103. Hill MA, Mantzoros C, Sowers JR. Commentary:
COVID-19 in patients with diabetes. Metabolism. 2020;107:154217. doi: 10.1016/j. metabol.2020.154217

104. Guan WJ, Ni ZY, Hu Y, et al. Clinical Characteristics of Coronavirus Disease 2019 in China. N Engl J Med. 2020; 382(18):1708-1720. doi: 10.1056/NEJMoa2002032

105. Hussain A, Bhowmik B, do Vale Moreira NC. COVID-19 and diabetes: Knowledge in progress. Diabetes Res Clin Pract. 2020;162:108142. doi: 10.1016/j. diabres.2020.108142

106. Allard R, Leclerc P, Tremblay C, Tannenbaum TN. Diabetes and the severity of pandemic influenza $A$ (H1N1) infection. Diabetes Care. 2010;33(7):14911493. doi: $10.2337 / \mathrm{dc} 09-2215$

107. Ren $H$, Yang $Y$, Wang F, et al. Association of the insulin resistance marker TyG index with the severity and mortality of COVID-19. Cardiovasc Diabetol. 2020;19(1):58. doi: 10.1186/s12933-020-01035-2

108. Li J, Wang X, Chen J, Zuo X, Zhang H, Deng A. COVID-19 infection may cause ketosis and ketoacidosis. Diabetes Obes Metab. 2020:10.1111/dom.14057. doi: 10.1111/ dom.14057

109. Chee YJ, Ng SJH, Yeoh E. Diabetic ketoacidosis precipitated by Covid-19 in a patient with newly diagnosed diabetes mellitus. Diabetes Res Clin Pract. 2020;164:108166. doi: 10.1016/j.diabres.2020.108166

110. Guo L, Shi Z, Zhang Y, et al. Comorbid diabetes and the risk of disease severity or death among 8807 COVID-19 patients in China: a meta-analysis. Diabetes Res Clin Pract. 2020;166:108346. doi: 10.1016/j. diabres.2020.108346

111. Abdi A, Jalilian M, Ahmadi Sarbarzeh P, Vlaisavljevic Z. Diabetes and COVID-19: A systematic review on the current evidences. Diabetes Res Clin Pract. 2020;166:108347. doi: 10.1016/j.diabres.2020.108347

112. Liu Z, Li J, Huang J, et al. Association Between Diabetes and COVID-19: A Retrospective Observational Study With a Large Sample of 1,880 Cases in Leishenshan Hospital, Wuhan. Front Endocrinol (Lausanne). 2020c;11:478. doi: 10.3389/fendo.2020.00478

113. Pontiroli $A E$, La Sala L, Chiumello D, Folli F. Is blood glucose or obesity responsible for the bad prognosis of COVID-19 in obesity -diabetes? Diabetes Res Clin Pract. 2020:108342. doi: 10.1016/j.diabres.2020.108342

114. Badawi A, Ryoo SG. Prevalence of comorbidities in the Middle East respiratory syndrome coronavirus (MERS-CoV): a systematic review and meta-analysis. Int J Infect Dis. 2016; 49:129-133. doi: 10.1016/j. ijid.2016.06.015

115. Dariya B, Nagaraju GP. Understanding novel COVID-19: Its impact on organ failure and risk assessment for diabetic and cancer patients. Cytokine Growth Factor Rev. 2020;53:43-52. doi: 10.1016/j.cytogfr.2020.05.001

116. Fan $\mathrm{C}, \mathrm{Wu} \mathrm{X}, \mathrm{Liu} \mathrm{Q}$, et al. A Human DPP4-Knockin Mouse's Susceptibility to Infection by Authentic and Pseudotyped MERS-CoV. Viruses. 2018;10(9):448. doi: 10.3390/v10090448

117. Akbar DH. Urinary tract infection. Diabetics and nondiabetic patients. Saudi Med J. 2001;22(4):326-329. PMID: 11331489

118. Jing Liang J, Liu J, Chen Y, et al. Characteristics of laboratory findings of COVID-19 patients with 
comorbid diabetes mellitus. Diabetes Res Clin Pract. 2020; 22:108351. doi: 10.1016/j.diabres.2020.108351

119. Wysocki J, Ye M, Soler MJ, et al. ACE and ACE2 activity in diabetic mice. Diabetes. 2006;55(7):2132-2139. doi: 10.2337/db06-0033

120. Yamamoto N, Matsuyama S, Hoshino T, Yamamoto $\mathrm{N}$. Nelfinavir inhibits replication of severe acute respiratory syndrome coronavirus 2 in vitro. BioRxiv. 2020. doi: 10.1101/2020.04.06.026476

121. Rao S, Lau A, So H-C. Exploring Diseases/Traits and Blood Proteins Causally Related to Expression of ACE2, the Putative Receptor of SARS-CoV-2: A Mendelian Randomization Analysis Highlights Tentative Relevance of Diabetes-Related Traits. Diabetes Care. 2020:dc200643. doi: 10.2337/dc200643

122. Muniyappa R, Gubbi S. COVID-19 pandemic, coronaviruses, and diabetes mellitus. Am J Physiol Endocrinol Metab. 2020;318(5):E736-E741. doi: 10.1152/ajpendo.00124.2020

123. Chen X, Hu W, Ling J, et al. Hypertension and Diabetes Delay the Viral Clearance in COVID-19 Patients. medRxiv. 2020c:2020. doi: 10.1101/2020.03.22.20040774

124. Cefalu WT, Hu FB. Role of chromium in human health and in diabetes. Diabetes Care. 2004;27(11):27412751. doi: $10.2337 /$ diacare.27.11.2741

125. Mehta P, McAuley DF, Brown M, Sanchez E, Tattersall RS, Manson JJ, HIh Across Speciality Collaboration UK.: COVID-19: consider cytokine storm syndromes and immunosuppression. Lancet. 2020;395(10229):10331034. doi: 10.1016/S0140-6736(20)30628-0

126. Gao Y, Li T, Han M, et al. Diagnostic utility of clinical laboratory data determinations for patients with the severe COVID-19. J Med Virol. 2020;92(7):791-796. doi: 10.1002/jmv.25770

127. Wu C, Chen X, Cai Y, et al. Risk Factors Associated With Acute Respiratory Distress Syndrome and Death in Patients With Coronavirus Disease 2019 Pneumonia in Wuhan, China. JAMA Internal Medicine. 2020;180(7):934-943. doi: 10.1001/ jamainternmed.2020.0994

128. Xu Z, Shi L, Wang $Y$, et al. Pathological findings of COVID-19 associated with acute respiratory distress syndrome. The Lancet Respiratory Medicine. 2020;8(4):420-422. doi: 10.1016/\$22132600(20)30076-X

129. Pal R, Bhadada SK. COVID-19 and non-communicable diseases. Postgrad Med J. 2020;96(1137):429-430. doi: 10.1136/postgradmedj-2020-137742

130. Yang JK, Feng Y, Yuan MY, et al. Plasma glucose levels and diabetes are independent predictors for mortality and morbidity in patients with SARS. Diabet Med. 2006;23(6):623-628. doi: 10.1111/j.14645491.2006.01861.x

131. Iqbal A, Prince LR, Novodvorsky P, et al. Effect of hypoglycemia on inflammatory responses and the response to low-dose endotoxemia in humans. I Clin Endocrinol Metab. 2019;104(4):1187-1199. doi: 10.1210/jc.2018-01168

132. Rubino F, Amiel SA, Zimmet $P$, et al. New-Onset Diabetes in Covid-19. N EnglJ Med. 2020. doi: 10.1056/ NEJMc2018688

133. Joshi SR, Tiwaskar MH, Shah SN. COVID-19: Diabetes and Obesity API-ICP Recommendations. I Assoc Physicians India. 2020;68(5):42-44. PMID: 32610865

134. Gupta R, Hussain A, Misra A. Diabetes and COVID-19: evidence, current status and unanswered research questions. Eur J Clin Nutr. 2020;74:864-870. doi: 10.1038/s41430-020-0652-1

135. Bhadada S.K. Should anti-diabetic medications be reconsidered amid COVID-19 pandemic?. Diabetes Res Clin Pract. 2020:163108146 doi: 10.1016/j. diabres.2020.108146

136. Mirabelli M, Chiefari E, Puccio L, Foti DP, Brunetti A. Potential Benefits and Harms of Novel Antidiabetic Drugs During COVID-19 Crisis. Int J Environ Res Public Health. 2020;17(10):3664. doi: 10.3390/ ijerph17103664

137. Brufsky A. Hyperglycemia, hydroxychloroquine, and the COVID-19 pandemic. J Med Virol. 2020:6. doi: $10.1002 /$ jmv. 25887 